\title{
Nothingness A Philosophical Reflexion
}

\author{
Luis A Pando Orellana* \\ Neuropsychiatrist-Immunologist, Mexico
}

*Corresponding author: Luis A Pando Orellana, Neuropsychiatrist-Immunologist, Mexico.

Received Date: September 19, 2019

Published Date: September 23, 2019

\section{Editorial}

In very many ways it does and has been one of the main questions in ontological thoughts along history since the Greeks. The eternal to be or not to be from Hamlet to Jean Paul Sartre which takes us to understand the anti-values of Jean Genet as a victim or executioner in a society that thinks eternity as a given present from a God that does not intervene in history and gives us the chance to save ourselves?? We are not saving anybody and biology determines our species fate: a fate ,that started once life was implanted in this tiny blue dot, in the solar system in a the far extreme peripheral position, almost impossible to contact other biological systems in a very vast universe also conceived as multiverse. Our finiteness reminds us of our, up to now, useless struggle to maintain fitness associated to a long life, as a success expression in face of a terrifying end in a short or long conceived period of time, with unavoidable sense of nothingness.

Once, I was having a conversation with a friend, that had always lived with his only wife, according to catholic dogmas and practices even community related effort to live as the new testament's teachings. A complete failure due to the usual arguments that some supported the community better than others. The result was a complete withdrawal from several families of such a program. Several years later his wife died of Alzheimer disease. We were chatting and suddenly this very good catholic, looking at me said; Luis, there is nothing in the afterlife.

Few months later, he died: and we continue, his family and friends to live with his surprising conclusion and declaration of his new faith based on "facts"? Catholic church has insisted based on theological thought that faith is an issue ,totally independent from any scientifical reference ;it is more like a conviction based on a feeling that as this given gift of life, so it is a trans life-afterlife gift of eternity with our own identity in this life and afterlife.

With this dogmatic believe, most catholics wander through life (as well as other religions) waiting for eternal gift in the afterlife and of course in the company of the beloved ones. Culturally speaking paradises give hope to transcend to a better life. Within this magical perception, explained as such to an overwhelming analphabetic population Even in those that have 4-10 years of basic education, gives the impression of suitable in order not to lose hope in an otherwise hopeless situations like wars, famine, pandemics and Death.

On the other hand, people with formal or informal education, search for explanations in the logical context of words and true meaning and application to our everyday life, for complex terms and its definitions of:

- $\quad$ Being

- $\quad$ Value

- $\quad$ Fate

- $\quad$ Finiteness

- Dogma

- $\quad$ Hope

- $\quad$ Eternity

- $\quad$ Death

- $\quad$ Nothingness

I will try to form something like algorithms as alternative ways of thinking that we the people choose in order to survive this quest of being alive and further in different scenarios from microcosmos to macro cosmos and how it affects our believes and evidence our inner but common fears.

\section{First There is the Socratic Way of Facing Several of this Clue Words}

In facing its sentence from the Athenian government Socrates ,decided to obey the law, and expecting the messenger from the judicial system with the poison, his family started to cry and he dismissed them, later his pupils did the same and using his typical 
pedagogical way of learning through questioning, Socrates advised them to think what is death? He advanced proposing two scenarios: one in which after death we incorporate ourselves to what he called eternal dream, from which by the way we came to this life. The exact implication he did not give but gives us the tranquility of not being conscious.

The second was: well if there is an afterlife (he immediately focuses to a similar way of life: and with a cultural bias, talks about interviewing people that he wished to meet and all over continue learning. Clearly, he proposes two only possible scenarios: Either face nothingness or something else we do not know. At the same time, when facing his executioner, he asks to be informed about the effects of the poison, expressing that knowing what is coming to us ,is the best way to psychologically be prepared and avoid or at least not be taking by surprise either by (and this is my own thought as physician)pain, suffocation or any other disagreeable effect like Fear.

By this mechanism, Socrates was provoking a very good effect of detachment. There is no other way to face the inevitable but by detachment. In other words, eliminate attachment, caring for the important question to be faced immediately and propose the only two scenarios that are possible: Nothingness, or else? There are so many deaths occurring in everyday life, some quite absurd, many in the context of war or social unrest, other seem accidental or because of multiple diseases and others provoked like in suicidal attempts. There are acute deaths or sudden, others seem chronical: question is: is death the same for everybody? Is everybody with the same awareness of what is happening or there are types of processes?

Let us think that yes, dying is the same but timing is not and the process neither. Sometimes we have a long time to prepare, sometimes it is sudden. Any way death statistically speaking is what any human being must expect some time in the course of his life. Nothingness should be contemplated or else. We will analyze both situations: The fear of death is no other than the fear of nothingness, but aside from this issue after it happens there is nothing left to feel or fear. It is the end. The biological processes of systemic failure, also gives the brain a chance to protect itself from fear but how?

Stress provoques hyperventilation and respiratory alkalosis enables the production of beta endorphins that inhibit the liberating factors of ACTH and glucagon that altogether change the perception of reality. And what happens if perception is changed? Brain enters into a delusional state that takes its reference from memory and objectal references. Everything goes fast in time, backwards and inwards. So, as a game of memories and going back into time (because that is what memory is about) we travel by means of the neural networks into our memories stored as algorithms and holograms from reality? To: stored holograms to: arquetypical memory until we reach what I dare to call molecular memory the very image of the composition of the universe and as we reach this level, through the thermodynamic laws we stick to this last frontier of memory and transform ourselves into this universal memory. This is another way of looking to nothingness, because we re-integrate to cosmos and leave the carcasses to go back into the earth as dust or ashes. The pain or suffocation is only a first reflex response to dying and we pass rapidly to the other stages.

But what about god and religion? The very storing and genesis of dogma: Mankind-human- kind need this as a search for security and the creation of aesthetical dimension to bear the ongoing suffering ( for the majority, of being alive) and the delusion of few, through power and control,which permit them to forget our finitude. I know this sounds wild but makes sense at least from the philosophy of science and mystical point of view, and can understand the process when you have been on the brink of death and unconsciousness. or experiences when the sensory is pushed to some level of going back through memory "traveling". This is when individuality loses its meaning

This is when we transcend the human into what once was known as ethereal when our deductive thought was constricted to the period and time in history: what we have developed as a culture. This is the true essence of learning.

- What different philosophical currents have managed as re-encarnation?

- $\quad$ Do we really exist in parallel universes?

- Do ourselves in other universes continue alternative versions of ourselves but in different environments?

- $\quad$ Different stories of ourselves as statistical possibilities when a function tends to infinity???

- Do we repeat ourselves through unending loop?

- What would be a form of leak into our reality of these hypothesis?

- Does the universe manage good and bad in our actions? Just from unjust?

To the question: will we be back? If time and space are the same, only through time loops can we re-live our story, but can we modify it? Let us imagine that the loop in time introduces a leak of information to a parallel universe: The flowing aspects of indetermination and quantum mechanics. This phenomenon could explain the ja-vu phenomena in our lives or encounters that seem to be out of the blue, paranormal phenomena or dissociation "mind? / body. All of them as quanta that strikes our sensorial networks. But back with another way of being? with a history of being? We are matter and matter we stay, but what are the odds for this sublimated matter to fit another being? Is the soul a kind of ID like DNA that fits in another molecular being? Like molecules within receptors and starts the molecular machinery like a biological vector? If so then it would be possible. But the simplest and biologically saving energy process would have the best chance for being carried out.

\section{Acknowledgement}

None.

\section{Conflicts of Interest}

No conflicts of interest. 